\title{
Higher-order correlations in non-stationary parallel spike trains: statistical modeling and inference Benjamin Staude* and Stefan Rotter
}

\author{
Address: Bernstein Center for Computational Neuroscience, Freiburg, Germany \\ Email: Benjamin Staude* - staude@bccn.uni-freiburg.de \\ * Corresponding author
}

from Eighteenth Annual Computational Neuroscience Meeting: CNS*2009

Berlin, Germany. 18-23 July 2009

Published: 13 July 2009

BMC Neuroscience 2009, I0(SuppI I):PI08 doi:I0.II86/I47I-2202-I0-SI-PI08

This abstract is available from: http://www.biomedcentral.com/I47I-2202/I0/SI/PI08

(c) 2009 Staude and Rotter; licensee BioMed Central Ltd.

\section{Introduction}

Understanding the cooperative dynamics of large neuronal groups is a major topic in current brain research. A particularly controversial issue has been the extent to which groups of neurons exhibit higher-order correlations in their firing patters [1]. Higher-order correlations are a signature of the temporal coordination of action potentials across neurons and are considered to be a powerful mechanism to cooperatively compute and transmit information in neuronal pools [2]. Currently available analysis tools, however, require vast sample sizes [3], rendering the analysis of massively parallel spike trains $(\mathrm{N}>10)$ for higher-order correlations essentially impossible.

\section{Background}

We have recently presented a novel method for a cumulant-based inference of higher-order correlations (CuBIC) that avoids the need for extensive sample sizes $[4,5]$. This is achieved by: a) exploiting constraining relations among correlations of different orders and b) estimating correlations among spike trains by the cumulants of the superimposed and discretely sampled spiking activity of all recorded neurons (population spike counts). Combining these concepts, CuBIC infers the presence of higher-order correlations from only few lower-order cumulants, which drastically reduces the requirements with respect to sample size as compared to previous approaches.

CuBIC employs the Compound Poisson Process as a statistical model for the population spike counts, where cor- relations are induced by the insertion of additional coincident events in continuous time, i.e. before the binning is applied [6]. In its current form, CuBIC furthermore assumes all spike trains to be stationary, an assumption which is often violated in standard experimental protocols.

\section{Results}

Here, we present a non-stationary version of the compound Poisson process by decoupling the correlation structure from the intensity of the population. Using the "law of total cumulance", we incorporate common, population-wide non-stationarities into the computation of the cumulants of the population spike counts. These rateadjusted cumulants are then utilized to adapt CuBIC to infer higher-order correlations even from non-stationary data stretches. The performance of the proposed adaptation is illustrated via numerical simulation.

\section{Acknowledgements}

We are grateful to Stuart Baker and Sonja Grün for fruitful discussions. Supported by the German Federal Ministry of Education and Research (BMBF grant 0IGQ0420).

\section{References}

I. Shlens J, Field GD, Gauthier IL, Grivich MI, Petrusca D, Sher A, Litke AM, Chichilnisky EJ: The Structure of Multi-Neuron Firing Patterns in Primate Retina. J Neurosci 2006, 26:8254-8266.

2. Abeles M: Corticonics Cambridge: Cambridge University Press; 1991.

3. Martignon L, Deco G, Laskey K, Diamond M, Freiwald W, Vaadia E: Neural Coding: Higher-Order Temporal Patterns in the Neurostatistics of Cell Assemblies. Neural Comput 2000, | 2:262|-2653. 
4. Staude B, Rotter S, Grün S: Detecting the existence of higherorder correlations in multiple single-unit spike trains. Proc of Society for Neuroscience 2007.

5. Staude B, Rotter S, Grün S: CuBIC: cumulant based inferrence of higher-order correlations in massively parallel spike trains. Submitted

6. Ehm W, Staude B, Rotter S: Decomposition of neuronal assembly activity via empirical de-Poissonization. EJS 2007, I:473-495.

Publish with Bio Med Central and every scientist can read your work free of charge

"BioMed Central will be the most significant development for disseminating the results of biomedical research in our lifetime. " Sir Paul Nurse, Cancer Research UK

Your research papers will be:

- available free of charge to the entire biomedical community

- peer reviewed and published immediately upon acceptance

- cited in PubMed and archived on PubMed Central

- yours - you keep the copyright

Submit your manuscript here:

http://www.biomedcentral.com/info/publishing_adv.asp 